\title{
A PANDEMIA E O DiREITO dE CONTINGÊNCIA: ALgumas RESPOSTAS A UMA PROVA INACABADA
}

\author{
Covid-19 pandemic and Contingency Law: \\ SOME ANSWERS TO AN UNFISHED PROOF
}

\begin{abstract}
Carla Amado Gomes
Professora Associada da Faculdade de Direito da Universidade de Lisboa. Investigadora do Centro de Investigação de Direito Público. Professora Convidada da Faculdade de Direito da Universidade Católica Portuguesa (Porto). ORCID: [https://orcid.org/0000-0002-6484-0549]. carlamadogomes@fd.ulisboa.pt

Recebido em: 03.04.2021

Aprovado em: 20.05 .2021 DOI: [https://doi.org/10.48143/rdai.18.cag]
\end{abstract}

ÁreAS do DIRETTO: Internacional; Direitos Humanos

Resumo: A pandemia originada pela disseminação do coronavirus transtornou profundamente os nossos hábitos de vida e constitui um desafio socioeconómico como não conhecêramos no pós Il Guerra mundial, ainda no século passado. 0 Direito, enquanto fenómeno de regulação social, foi igualmente posto à prova, nas suas capacidades conformativas e adaptativas. Este texto pretende, por um lado, lançar uma visão panorâmica sobre as respostas dos Estados-membros da Uniäo Europeia aos problemas constitucionais colocados pela necessidade de gestão da pandemia e, por outro lado, sinalizar aspectos que deverão constituir lições para o futuro.

Palavras-chave: Covid-19 - Estado de excepção - Direito de contingência.
ABSTRACT: The pandemic caused by the spread of the coronavirus has profoundly deranged our habits of life and constitutes a socioeconomic challenge as we have not known in the postWorld War II. Law, as a phenomenon of social regulation, was also put to the test, in its conformative and adaptive capacities. This text aims, on the one hand, to provide an overview of the responses of the Member States of the European Union to the constitutional problems posed by the need to manage the pandemic and, on the other hand, to point out aspects that should constitute lessons for the future.

Kerwords: Covid-19 - State of exception - Contingency law. 
Sumárı: 1. Enquadramento breve de uma euro-ordem em crise. 2. 0 quadro operativo de resposta à crise epidémica. 3 . A redistribuição de competências no seio da estrutura do Estado. 4. A garantia do controlo político pelo Parlamento. 5. A importância dos meios telemáticos na actividade parlamentar. 6 . A garantia do controlo judicial das medidas de contingência. 7. Os imprescindiveis parâmetros proporcionalidade e não discriminação. 8.0 inarredável principio da responsabilização extracontratual do Estado. 9. A legitimação técnica das medidas de contingência. 10.0 "direito a saber" num quadro de profunda incerteza. 11. A supervisão supranacional das medidas restritivas dos direitos humanos pela Corte Europeia dos Direitos do Homem.

\section{Enguadramento ${ }^{1}$ BREVE de uma eURO-ORDEM EM CRISE}

"Resiliência" é um termo muito utilizado no Direito das catástrofes. Segundo o Merriam Webster Dictionary ${ }^{2}$, pode querer significar a capacidade de suportar um choque sem deformação ou ruptura - o que corresponde a flexibilidade - ou a tendência para recuperar facilmente em face de uma adversidade ou mudançao que associo a adaptabilidade. No contexto da crise que atravessamos, muito se tem falado de resiliência e facilmente se compreende a utilidade de tal conceito para enfrentar um risco (aparentemente) natural como o que vivemos. A incerteza, por seu turno, é um factor que põe à prova os decisores e os mecanismos de decisão, que devem ser permeáveis à mudança súbita e sujeitos a revisão constante. Quando se enfrenta um fenómeno sobre o qual nem os cientistas parecem ter uma base mínima de inteligibilidade, avaliar o risco, prever as medidas necessárias e gerir a informação transmissível ao público constitui um enorme e verdadeiramente inédito desafio. O Direito de contingência - ou de emergência - visa contribuir para a resiliência do sistema jurídico através da gestão dinâmica da incerteza.

Podemos estar perante (mais) um teste em face da maior crise que ainda havemos de enfrentar: a da perda irrecuperável das bases de vida humana no Planeta, tal como a conhecemos. Recorrendo à imagem sugerida por Miguel Nogueira de Brito, "Desde a crise de segurança provocada pelos ataques terroristas, da crise financeira e económica, passamos agora pela crise sanitária e epidemiológica, porventura em direção à grande crise climática que se segue: os quatro cavaleiros do apocalipse que reconfigurarão o modo como concebemos as situações de

1. Texto originalmente publicado na RDA - Revista de Direito Administrativo, n. ${ }^{\circ} 9,2020$, pp. 33-43. ISSN 2184-1799.

2. https://www.merriam-webster.com/dictionary/resilient. 
- As pessoas normalmente fazem escolhas sensatas, se estiverem cientes das circunstâncias e dos seus objectivos. Mas para tanto necessitam de informação-logo, os comunicadores devem assumir a responsabilidade de fornecer boa informação em tempo útil.

Este quadro ideal pode complicar-se em face dos dados concretos. No caso da actual pandemia, o enigma da avaliação do número de infectados (pois seria necessário testar toda a população, semanalmente, uma vez que a maioria das pessoas contaminadas é assintomática, além de não há certeza de que quem contrai a doença e é dado como curado não possa voltar a infectar-se), a incerteza quanto às formas de propagação da doença, o surgimento de informações contraditórias no seio da OMS, a difusão de estudos vários com conclusões díspares sobre o vírus, por um lado, e a exploração sensacionalista de toda esta confusão pela imprensa, por outro lado, faz da tarefa de comunicação um desafio de vulto.

A actual pandemia constitui um teste a esta lista de boas práticas, em razāo da conjugação dos factores extensão temporal / alteração drástica de hábitos quotidianos / reflexo económico significativo / contraditoriedade das informações sobre as medidas adoptadas. Quanto mais volátil for o cenário e maior duração adquirir o constrangimento, maior será a tendência para relaxar a percepção do risco e o comportamento preventivo individual e colectivo, reclamando criatividade e eficácia na comunicação $0^{38}$. O controlo da "infodemics" (epidemia informacional) é igualmente essencial para criar um clima de confiança e alguma previsibilidade na evolução positiva da situação ${ }^{39}$.

\section{A SUPERVISÃO SUPRANACIONAL DAS MEDIDAS RESTRITIVAS DOS DIREITOS humanos PEla Corte Europeia dos DiReitos dO HOMEM}

Tendo em atenção que todos os Estados membros da União Europeia são partes na Convenção Europeia dos Direitos do Homem, e que todos (à excepção da Suécia) adoptaram estratégias agressivas de combate à epidemia traduzidas em suspensão de um conjunto significativo de liberdades fundamentais ou restrições às

38. Um estudo realizado em Fevereiro sobre comunicação e percepção do risco de contrair a COVID-19 na Finlândia pode ver-se aqui: https://www.eurosurveillance.org/docserver/ fulltext/eurosurveillance/25/13/eurosurv-25-13-4.pdf? expires $=1594508816 \&$ id=id\&accname=guest\&checksum=9547D3F0FDAD54688BD52E72F55ADFCB.

39. Cf. o Comunicado da OMS Risk communication and community engagement readiness and response to coronavirus disease (CVID-19) - https://apps.who.int/iris/bitstream/ handle/10665/331513/WHO-2019-nCoV-RCCE-2020.2-eng.pdf. 
$\operatorname{mesmas}^{40}$, seria de esperar que o mecanismo do artigo $15^{\circ}, \mathrm{n}^{\circ} 3$ da Convenção tivesse sido accionado para sinalizar a "derrogação" de direitos e a retoma da normalidade. Com efeito, a pandemia pode ser entendida como um perigo público que ameaça a vida da Nação, nos termos do $\mathrm{n}^{\circ} 1$ do mesmo preceito, havendo assim necessidade de comunicar a alteração temporária da normalidade ao Secretário do Conselho da Europa ${ }^{41}$. Seja porque os Estados desconsideram a pandemia, apesar da sua gravidade, como um "perigo para a vida da Nação", seja porque preferem manter a estratégia restritiva menos visível - como se isso fosse possível na sociedade de informação em rede que temos -, apenas Letónia e Roménia o fizeram ${ }^{42}$.

Poder-se-ia questionar, desde logo, a legitimidade desse comportamento dos Estados à luz da injunção de transparência induzida pelo artigo $15^{\circ}$ da Convenção Europeia dos Direitos do Homem. Porém, ainda que se entenda que a pandemia, facto notório, constitui um evento de extrema gravidade, as capacidades dos Estados para lhe fazer face variam e pode haver razões para ser descaracterizada como um "perigo que ameaça a vida da Nação", pelo que nem responsabilidade internacional caberá por inobservância da comunicação.

A ausência de comunicação não neutraliza, todavia, a existência de futuras acções contra Estados que tenham adoptado medidas desconformes com a Convenção, nomeadamente no plano da obrigação de não discriminação (cf. o artigo $14^{\circ} \mathrm{da}$ Convenção). A tutela providenciada pela Corte Europeia dos Direitos do Homem, a verificarem-se atropelos e após a exaustão dos recursos internos, será meramente indemnizatória, mas ainda assim terá simultaneamente um efeito pedagógico e preventivo de casos idênticos num cenário que pode muito bem voltar a repetir-se, com este vírus ou outros ${ }^{43}$.

40. Sobre a diferenciação entre restrições e derrogações de direitos na CEDH, Ana Maria GUERRA MARTINS, O Impacto da COVID 19 nos Direitos Humanos - A resposta da Convençāo Europeia dos Direitos Humanos, e-Pública, 2020/1, pp. 153 segs, 158-161.

41. Neste sentido, Alessandra SPADARO, COVID-19: Testing the limits of human rights, European Journal of risk regulation, 2020/2, pp. 317 segs, 322; Ana Maria GUERRA MARTINS, O Impacto da COVID 19..., cit., p. 162 (indicando jurisprudência do TEDH na qual se abordou o conceito).

42. https://www.coe.int/en/web/conventions/full-list/-/conventions/webContent/62111354.

43. Sobre a protecção internacional do direito à saúde contra medidas discriminatórias no contexto de epidemias (a propósito do vírus Ebola), Esther PEARSON, Towards human rights-based guidelines for the response to infectious disease epidemics: righting the response, Australian Journal of Human Rights, 2018/2, pp. 202 segs - https://scholar. google.pt/scholar? q=Esther+PEARSON,+Towards+human+rights-based+guidelines+for+the+response+to+infectious+disease+epidemics:+righting+the+response\&hl=pt-PT\&as_sdt=0\&as_vis $=1$ \&oi=scholart. 


\section{Pesauisas do Editorial}

\section{Veja também Doutrinas relacionadas ao tema}

- Diretivas antecipadas de vontade em tempos de pandemia, de Maria Gabriela Venturoti Perrotta RDM 6 (DTR|2020|8725);

- Faisca na economia pandêmica: a incapacidade superveniente de prestar, de Alexsandra Marilac Belnoski, Antonio Deccache, Muriel Waksman, Haroldo Malheiros Duclerc Verçosa e Jayme Petra de Mello Neto - RDB 91/159-203 (DTR|2021|1992); e

- Pandemia, caso fortuito e imprevisão, de Rogério Donnini - RDCC 27/33-43 (DTR/2021|9113). 
